November - 2004

\title{
Bounded Community: Designing and facilitating learning communities in formal courses
}

\author{
Brent G. Wilson \\ University of Colorado at Denver \\ USA \\ Stacey Ludwig-Hardman \\ Western Governors University \\ USA \\ Christine L. Thornam \\ Nurse-Family Partnership \\ USA \\ Joanna C. Dunlap \\ University of Colorado at Denver \\ USA
}

\begin{abstract}
Learning communities can emerge spontaneously when people find common learning goals and pursue projects and tasks together in pursuit of those goals. Bounded learning communities (BLCs) are groups that form within a structured teaching or training setting, typically a course. Unlike spontaneous communities, BLCs develop in direct response to guidance provided by an instructor, supported by a cumulative resource base. This article presents strategies that help learning communities develop within bounded frameworks, particularly online environments. Seven distinguishing features of learning communities are presented. When developing supports for BLCs, teachers should consider their developmental arc, from initial acquaintance and trustbuilding, through project work and skill development, and concluding with wind-down and dissolution of the community. Teachers contribute to BLCs by establishing a sense of teaching presence, including an atmosphere of trust and reciprocal concern. The article concludes with a discussion of assessment issues and the need for continuing research.
\end{abstract}

A version of this paper was presented at the meeting of the American Educational Research Association (AERA), San Diego, April 2004. Please send inquiries to Brent G. Wilson (brent.wilson@cudenver.edu). [Additional contact information: Brent's phone: 303-556-4363; fax 303-556-4479]

Keywords: learning community; instructional design; emergent systems; collaborative learning; teaching presence; sense of community 


\section{Bounded Community: Designing and facilitating learning communities in formal courses}

New theories of culture-mediated cognition and advances in distributed-learning platforms have prompted interest in learning communities among instructional technologists. Lave and Wenger's (1991) communities-of-practice model led to a number of workplace innovations, but also to instructional environments that rely on collaborative forms of learning, sharing, inquiry, and group participation. In common with communities of practice, learning communities are instances of complex emergent systems wherein control is distributed among participants rather than centered in a hierarchical authority (Backroad Connections Pty Ltd, 2003). According to LudwigHardman (2003):

An online learning community is a group of people, connected via technology-mediated communication, who actively engage one another in collaborative learner-centered activities to intentionally foster the creation of knowledge, while sharing a number of values and practicesp (p. iv).

While a hands-off approach may work with some Web-based interest groups and groups sharing a common business purpose, establishing community within formal courses is often problematic. Educational courses, online or classroom-based, are not wholly voluntary, self-organizing groups. Rather, courses typically serve as required, encouraged, or elective components of a larger program of study - a degree, certificate, or credential of some kind. These programs may be voluntary in the sense that people freely choose to enter, but once in, they must adhere to the regimen mandated by the state, accrediting organization, or employer.

\section{Bounded Communities}

This leads to a different notion of learning community within a curriculum framework - bounded by the expectations inducing participation, but also by the timeframe of a typical course. Course participants come together for a standard, pre-determined period of time, sometimes a term or semester in length, but often for a shorter duration, especially for workplace learners. Course participants thus find themselves in a situation where:

- Participation is required in order to obtain a desired end

- They do not choose their classmates or instructor

- They must commit to a fixed length of time

- They must make an explicit effort to connect with others (by coming to school or connecting online).

These parameters affect the nature of community that may or may not take shape within a formal learning context. The formation of community within a course takes leadership, support, and facilitation. An instructor or facilitator needs considerable skill in this area, as well as resources, 'ools, and structures to assist the effort. Most teachers will affirm that emergence of community depends on a group's collective personality or character, and the distributed participation of group members. That participation, however, is mediated by the rules, incentives, and structures that together form the course infrastructure. Some rules and structures will contribute to the formation 
of community, while others work against its creation, for example, mandated individual assignments graded on a curve and other competitive structures.

Our use of the term bounded learning community denotes certain constraints placed on the community formation within course-based learning environments. The community experience is bounded by the parameters listed above. While parameters are normally thought of as constraints, they may also serve as affordances that enable certain kinds of learning and activities to transpire; for example, safely removed from work responsibilities, students may be able to share concerns or practice skills more freely. When appropriate conditions are met, a level of community can, indeed, be established in courses.

The purpose of the present paper is to develop the idea of bounded learning communities with reference to the professional literature, and to suggest strategies for supporting learning communities within formal courses, particularly those distributed to learners at a distance.

\section{Why Learning Communities?}

Interaction within courses often occurs between the teacher and the class, with individual students asking and answering questions while others listen. When those forms of interaction predominate, a sense of community does not really develop, yet students continue to attend, listen, interact occasionally, study, learn, and pass tests. Based on this teaching experience, many teachers, in classrooms and online, may question the need for learning communities, especially in contentintensive courses with a fixed curriculum. While we acknowledge and respect a number of different approaches to teaching, we offer three reasons why bounded e-learning communities should receive serious consideration:

\section{Learning communities provide a social context for the material}

Through collaborative work, students experience and develop an appreciation for multiple perspectives; refine their knowledge through argumentation, structured controversy, and the sharing of ideas and perspectives; learn to use colleagues as resources; and are more willing to take on the risk required to tackle complex, ill-structured problems (Dunlap and Grabinger, 2003).

\section{Students feel more connected within a community}

Students taking online courses often feel isolated and disconnected from the instructor and other enrolled students. Fostering a sense of community can reduce feelings of isolation, improve the learner's attitude toward the course and the content, and ultimately boost student retention (Ludwig-Hardman and Dunlap, 2003).

\section{Learning communities can serve as a bridge between school and work environments}

Solving authentic problems collaboratively within a course environment offers a safe but authentic practice field for acquisition or skills that will transfer to work situations (see Barab and Duffy, 2000). By participating in a learning community, students engage in the authentic culture of the discipline they are studying using the physical and mental tools of the discipline, thus 
preparing them for entry into communities of practice beyond the course (Dunlap and Grabinger, 2003). Similarly, a BLC provides opportunity for reflection, analysis, and study that often is neglected in a busy workplace environment.

In summary, we believe that most courses are richer and more authentic learning environments when learning communities are encouraged and supported. Even students in self-paced courses can benefit from linkage to a larger community of students. Granted, some courses focus entirely'on skill acquisition, and the skills in question may be technical and not collaborative in nature. On closer observation, however, those skills will need to be applied in a practical context, and then, almost surely, social variables will enter into play. Designers and instructors rightly should determine strategies most appropriate for their situation, but we do believe the use of a bounded learning community is a fairly robust teaching approach suitable for a wide range of situations and needs.

\section{Components of Learning Community}

Learning communities share essential qualities with Wenger's notion of communities of practice. Figure 1 presents Wenger's foundation for communities of practice. Essentially, participants must 1) be engaged in a joint enterprise, some compelling purpose or project that draws them together; 2) have common access to a shared repertoire of resources, including stories, concepts, and tools; and 3) maintain relationships through mutual engagement in trust-building activities. In classic form, communities of practice take shape within and around work organizations, playing off their structure and generally facilitating organizational ends.

Figure 1. Key components of communities of practice (from Wenger, 1998a, p. 73).

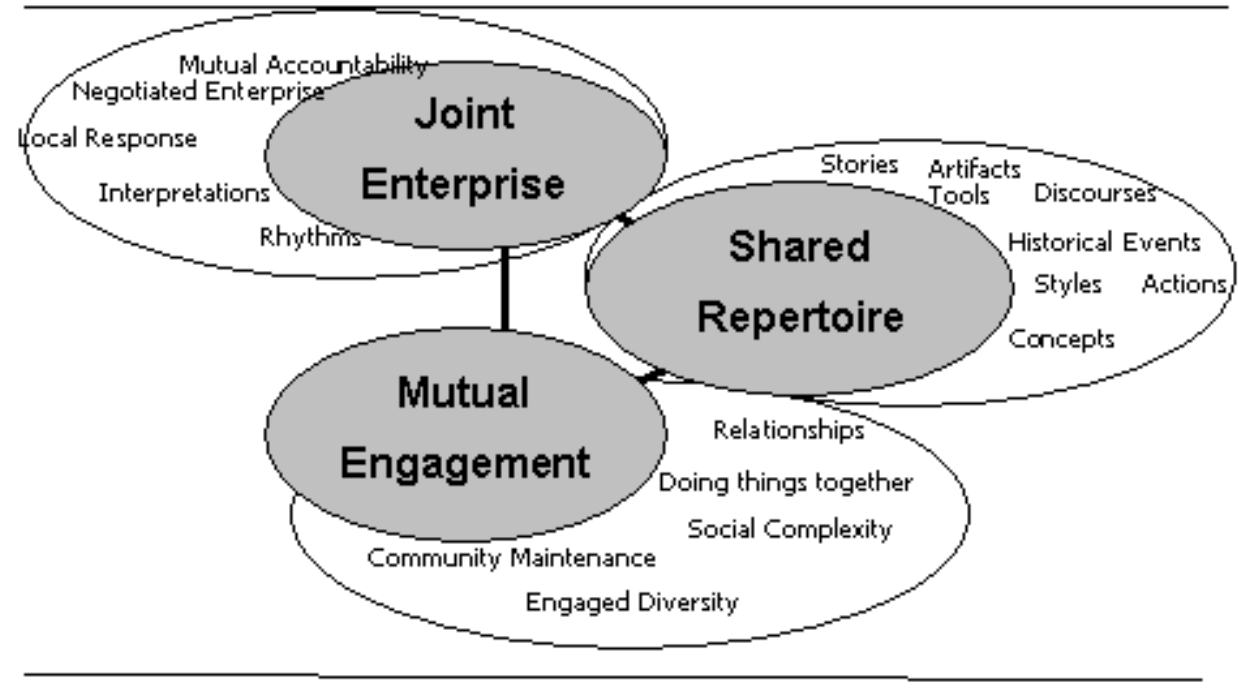

Bounded learning communities also depend upon the organization, in this case that of a training unit and a course for an underlying purpose and context of operation. Indeed, course-based learning communities can be seen as a special case of a community of practice, wherein:

1. The major enterprise is intentional learning, completing required activities, and performing well on course assessments

2. The group membership is based on course enrollment and team assignment 
3. Resources are shared and interactions conducted under the guidance of an instructor

In contrast to classic communities-of-practice formulations, substantial supports for course-based communities can and should be designed ahead of time by the instructor, anticipating the learning and collaborative needs of students. Based on Ludwig-Hardman's (2003) comprehensive review of the learning-community literature, we have identified seven features that seem to facilitate its creation: 1) shared goals; 2) safe and supportive conditions; 3) collective identity; 4) collaboration; 5) respectful inclusion; 6) progressive discourse toward knowledge building; and 7) mutual appropriation. These features are not strict criteria to be satisfied to develop a learning community, but they are qualities or features associated with learning communities, which should be considered when attempting to establish or support such communities in courses and programs.

\section{Shared Goals}

A learning community forms, in part, when individuals from multiple perspectives willingly collaborate as a larger collective whole toward a shared goal or vision (Barab and Duffy, 1998; Palloff and Pratt, 1998; Senge, 2000). "The sense of shared community requires that the participants be sympathetic to the ideas around which the group is based; even if they disagree, there needs to be some fundamental common ground" (Donath, 1999, p. 31). When members of a community share goals there is a greater desire to participate in activities and to contribute to the group's goals (Wilson, 2001). For example, students in a course may be assigned into working groups to complete a project, with a grade based on both individual and group performance. By establishing goals and rules that mandate interaction and co-dependence, students can develop a shared goal that gives real purpose in collaboration.

\section{Safe and Supporting Conditions}

A learning community provides caring and nurturing conditions that foster the development of trust and respect among the learners (Coombe, 1999; Retallick, 1999). This, in turn, encourages risk-taking, the exchange of ideas and feedback, shared responsibility and'support for learning and outcomes, and distributed or negotiated control (Barab and Duffy, 1998; Downes, 1998; Etzioni and Etzioni, 1997; Grabinger and Dunlap, 1996; Hiltz, 1998; Jonasen, Peck, and Wilson, 1999; Lawrence, 1997; Scime, 1994; Wells, 1999). The teacher's role in modeling respectful behavior in interactions is important, as is monitoring of interactions between students. Students often benefit by participating in establishing rules and norms for group interaction to ensure a safe and respectful environment.

\section{Community Identity}

The symbolic construction of a community is accomplished by:

... ensuring that the group is apart from and different from other social groups through the establishment of a group identity recognizable from within and outside of the group. The boundaries of community comprise the "face" presented to outsiders, "its collective public identity" (Calderwood, 2000, p. 1213). 
Clearly defined boundaries provide for inclusion and exclusion of members. Maintaining clear boundaries may encourage ongoing interaction and greater intimacy, and assurances that the learners' efforts will not be reaped by others who have not contributed to those efforts (Kollock, 1996). Boundaries also delineate roles between old-timers who have been stable members of the community and newcomers, allowing for the process of legitimate peripheral participation as newcomers move toward full participation in the community (Lave and Wenger, 1991).

A learning community's identity is largely formed by the community's history or heritage, including the shared goals and belief systems, rules and norms of the community that is reproduced as new generations of members enter the community to assure that it continues to function (Barab and Duffy, 1998; Scardemalia and Bereiter, 1996). A shared history also encourages the development of group identity, which enhances reproducibility as new members contribute, support, and eventually lead the community into the future (Barab, Barnett and Squire, 2000; Barab and Duffy, 2000; Lawrence, 1997).

On this point, however, bounded learning communities differ from more emergent varieties. The challenge for course designers is to establish nearly instant traditions that draw on traces of history but do not depend on a continuing line of group members. Achieving a rapid sense of community is a formidable challenge, according to the conventional wisdom:

[If members of a] group will not meet each other in the future, if there is no stability in the names and identities that people adopt, and if there is no memory or community record of previous interaction, it will be very difficult to create and maintain a cooperative online community (Kollock, 1996, p. 235).

The limited nature of contact and interaction in online courses can inhibit students identifying with the group. At surface levels, students may identify with the group and see themselves as partners and collaborators. Establishing deeper levels of identity change is rarer and may depend on the intensity of the learning experience and whether students encounter one another in continuing courses. Larger contextual factors may also be important, for example, students' sense of belonging within an academic or work program. In any case, identity remains an important consideration for learning communities, and can serve as a continuing goal for e-learning courses and environments.

\section{Collaboration}

Involvement in a learning community requires high levels of social interaction. Salomon and Perkins (1998) state: "learning to learn fundamentally involves learning to learn from others, learning to learn with others" (p. 17). Collaborative online learning communities provide community members the chance to learn from and with others and to contribute to others' learning.

Collaboration in e-learning environments is often a challenge for students. Essential preconditions such as getting everyone's contribution in a timely way can be difficult, depending on the mix of group members. Students' preconceived notions of what happens in an online course can also interfere with collaboration; many students still believe that online learning is like correspondence and, therefore, individualized and self-paced. "Weak" forms of collaboration, such as threaded discussion of assigned topics, are generally easier to sustain than stronger forms that require true negotiation, management, and decision-making. These stronger forms of 
collaboration may test a group's coherence, but if the group is successful in their work, bonds are strengthened and a true sense of connection established.

\section{Respectful Inclusion}

A learning community values and seeks to accommodate diversity of membership, opinions, and perspectives, along with authentic expression of those perspectives (Barab and Duffy, 2000; Brown and Campione, 1994; Jonassen, Peck and Wilson, 1999; Reil, 1996; Sergiovanni, 1999; Wellman and Gulia, 1999; Wells, 1999; Wenger, 1998b). At the same time, deep differences between group members can be a threat to coherence, especially if a means of resolving differences is not worked out. Online courses need clear rules and supports for including all group members in work and decision processes. Dewey (1916) asserted:

A society which makes provisions for participation ... of all its members ... is democratic. Such a society must have a type of education which gives individuals a personal interest in social relationships and controls, and the habits of mind which secure social changes without introducing disorder.

The topic of diversity and inclusion is a challenge for e-learning, perhaps more so than other environments because of the natural distancing felt by many learners. Some aspects of diversity (such as gender, age, ethnicity, learning challenge/ disability, etc.) are masked in an online setting. As in all forms of education, however, some learners' needs are not clearly addressed by the course, and these individuals will likely be lurking at the margins and not participating fully in collective tasks. People at a particular disadvantage include those not fluent in reading and writing; those unskilled in independent problem solving; and those lacking prior knowledge of the subject matter.

Based on best cases, successful learning communities can accommodate surprising levels of diversity in safe and supportive environments that invite risk-taking, learner control, and agency. Getting to that point of full engagement by every learner, however, will always be a challenge for course designers and instructors. And in general, finding effective means for respectful and full inclusion of all learners remains one of the challenging tasks in need of further research and development.

\section{Progressive Discourse toward Knowledge Building}

Bereiter (1994) proposed the term progressive discourse to describe the process by which the sharing, questioning, and revising of opinions leads to "a new understanding that everyone involved agrees is superior to their own previous understanding. Such discourse is based on four commitments that all participants make: a) to work toward common understanding; b) to frame questions and propositions in ways that allow evidence to be brought to bear on them; c) to expand the body of collectively valid propositions; and d) to allow any belief to be subjected to criticism if it will advance the discourse” (Bereiter, 1994, p. 6). Scardamalia and Bereiter (1994) further indicate that intentional learning is "fundamentally a matter of goals rather than strategies. It is a matter of having knowledge as a goal" (p. 201). It is the active and intentional pursuit of knowledge that distinguishes learning communities from other chance encounters or purely social ne'works (Palmer, 1999). Progressive discourse and intentional knowledge-building both help to differentiate learning communities from communities with other kinds of discourses and performance goals. 


\section{Mutual Appropriation}

Brown and Campione (1994) define mutual appropriation as the process by which "learners of all ages and levels of expertise and interests seed the environment with ideas and knowledge that are appropriated by different learners at different rates, according to their needs and to the current state of the zones of proximal development in which they are engaged" (p. 237; see also Vygotsky, 1978). Mutual appropriation refers to the bi-directional and reciprocal nature of learning in which members of the community are both learners and teachers (Butt, 1999; Sergiovanni, 1999).

Since active participation in a learning community takes time and effort, distance learners must perceive that there is some benefit to be gained from participation in a learning community and that they are getting a "personal return on their investment in the group" (Wilson and Ryder, 1996; see also Levin, 1995). Rogers (1995) calls this relative advantage, a sense that there will be some payoff or benefit to adoption of the new practice. Further, learners that perceive there is a mutual benefit will more likely feel a sense of obligation to "participate in activities and contribute to group goals" (Wilson, 2001). Mutual appropriation can provide intrinsic rewards and incentives to members who continue contributing as both learners and teachers within the community.

For design purposes, the seven features outlined above can serve as an organizing framework for interventions and strategies aimed as increasing community, offered later in the paper. Or, more holistically, course resources may be analyzed and determined to be strong or weak in one or more of the seven features, leading to adjustments in the environment, tasks, or support structures.

\section{The Teacher's Role}

Teachers are a critical component of bounded learning communities. They must:

- Provide the infrastructure for interaction and work, including syllabus, communication tools, and information resources

- Model effective collaboration and knowledge construction

- Apply instructional strategies

- $\quad$ Supervise student activities

- Monitor and assess learning, providing feedback, remediation, and grades

- Troubleshoot and resolve problems, including meeting needs of hard-to-reach students

- $\quad$ Establish trusting relationships with students

This last task, establishing trusting relationships with students, can sometimes be neglected in online environments. We believe this is a mistake, because online learners need to have confidence in their teachers as guides in their journey toward new learning. 
The remaining focus of this section is a discussion of teaching presence and its contributing role in bounded learning communities. To some extent, this discussion balances the technical features of learning communities established above and serves as a reminder of the qualitative, interpersonal foundations of course experiences.

Upon entering a new course environment, students observe and establish schemas for the course and instructor, adjusting their existing schemas, which are based on years of observation and experience in school situations. Depending on the design and details of the course and the messages sent from the instructor, students may feel varying levels of safety and trust. Because community-building depends on student initiative and willingness to take risks, establishing a trusting relationship with the teacher is an important precondition for successful learning communities.

Much of the current literature on presence is based on either psychometric notions of social distance or technical notions of presence as an illusion that a mediated experience is not'mediated (Lombard and Ditton, 1997). Thornam (2003) describes teaching presence focusing on the teacher-student relationship, grounded in the existential view of the obligation imposed when people make interpersonal demands on the other (e.g., Hand, 1989). Teaching presence is defined as:

... an intersubjective experience during which a teacher and a student willingly move together toward valued learning. By being there with the student, the teacher reduces the student's educational vulnerability and by knowing the student, feelings of helplessness or abandonment are allayed. Both submit to the power of the other to influence, penetrate and engage, and are equally willing to be changed by the experience (Thornam, 2003, p. 7).

Indicators of teaching presence are presented in Table 1 on the next page. 
Table 1. Themes supporting the construct of teaching presence, with associated attitudes, actions, and beliefs (adapted from Thomam, 2003, p. 54).

\begin{tabular}{|c|c|}
\hline Themes & Associated Attitudes, Actions and Beliefs \\
\hline $\begin{array}{l}\text { Interpersonal, } \\
\text { human } \\
\text { relatedness }\end{array}$ & $\begin{array}{l}\text { - Authentically relates and genuinely represents self to } \\
\text { students } \\
\text { - Interactions are beyond the mechanical- not rote } \\
\text { - Reveals self to the student (appropriate personal and } \\
\text { professional self-disclosure), i.e., does not just put on } \\
\text { another hat while teaching } \\
\text { - Joins with the student } \\
\text { - Communicates empathy for the educational vulnerability of } \\
\text { students; listens without judging } \\
\text { - Respects the dignity of the student by using a high degree } \\
\text { of immediacy in verbal communication, i.e., students are } \\
\text { not objectified }\end{array}$ \\
\hline $\begin{array}{l}\text { Believes in the } \\
\text { agency of the } \\
\text { student, that is, } \\
\text { sees students as } \\
\text { the causal agent } \\
\text { who largely self- } \\
\text { detemines their } \\
\text { own leaming }\end{array}$ & $\begin{array}{l}\text { - Advances students' efforts to become an independent and } \\
\text { intentional leamer } \\
\text { - Engages students in active leaming and riskful thinking } \\
\text { - Builds students' self-efficacy through participativel } \\
\text { affimative experiences }\end{array}$ \\
\hline $\begin{array}{l}\text { Mutual } \\
\text { willingness to be } \\
\text { available and by } \\
\text { the side of the } \\
\text { other }\end{array}$ & $\begin{array}{l}\text { - Is available to students and focused on them, even when } \\
\text { rushed } \\
\text { - Explains things at the student's level as many times as } \\
\text { needed } \\
\text { - Intellectually honest and demanding } \\
\text { - Holds self and student accountable for moving toward } \\
\text { valued leaming } \\
\text { - Issues reassurances, such as "I'll be right here" when the } \\
\text { underlying message is "Someone focused solely on your } \\
\text { [educational] welfare is present" (Gardner, 1991, p. 192). }\end{array}$ \\
\hline $\begin{array}{l}\text { Communicates } \\
\text { and dialogues } \\
\text { effectively with } \\
\text { students }\end{array}$ & $\begin{array}{l}\text { - Communicates and demonstrates expertise in the subject } \\
\text { matter } \\
\text { - Is personally committed to strengthening their own and } \\
\text { students' knowedge bases } \\
\text { - Maintains professional (teacher) self-efficacy }\end{array}$ \\
\hline $\begin{array}{l}\text { Trustworthily } \\
\text { pursues the } \\
\text { student's best } \\
\text { interest }\end{array}$ & $\begin{array}{l}\text { - Knows where to go and how to get there } \\
\text { - Enthusiastically leads students toward worthwhile leaming } \\
\text { goals with competenceiconfidence }\end{array}$ \\
\hline
\end{tabular}

Teachers should model community participation skills and values, including turn-taking, netiquette, thoughtful responses to peers' posts, and organization and facilitation of community events or chat. They should actively monitor the community discussions to answer questions, resolve conflicts, and guide discussion as needed. Students quickly pick up on the "absent" instructor, and take tasks less seriously when they sense its lower priority. Instructors can be deemed "absent," both literally and figuratively. Teachers can avoid being viewed as figuratively absent by relating meaningful personal and professional experience. 
The schemas students use to make sense of classrooms and online learning environments are largely based on the interactions they have with teachers and other students. Attitudes, actions, and beliefs associated with these two themes give us clues about strategies teachers can use to foster a strong sense of presence with students. Students then feel safer to engage in progressive discourse toward knowledge building, mutual appropriation, respectful inclusion, and collaboration, all of which are important elements in community formation.

\section{Ritualized Forms for Communities-in-Progress}

A key observation of Ludgwig-Hardman (2003) was that bounded learning communities have a developmental life cycle. Students are asked to engage in a pre-defined sequence where they first learn the ropes, then enter into intensive interaction with peers, then conclude the experience with reflection and some kind of ritualized closure experience. These three stages can be termed: initiation, participation, and closure respectively.

The developmental form of the course may become clearer to students if guiding symbols and artifacts are presented as part of the course structure. Cultural anthropologists have studied local communities for many years and have observed ways that communities express meaning and values through language and rituals. These cultural artifacts help community members make sense of their worlds and participate meaningfully in group activities. Trice and Beyer (1984) analyzed corporate cultures within business organizations, looking for rituals and rites that defined the community.

On the next page, in Figure 2 we apply these ideas to the design of courses. We present a set of questions intended to stimulate thinking about various forms of cultural artifacts and how they might be related to a bounded learning community. Designers of online courses could establish a number of signs, symbols, rituals, and language pointers to strengthen the developmental arc of the course and to encourage positive engagement in community interactions. 
Figure 2. Job aid for analyzing culture within a bounded learning community, based largely on categories from Trice and Beyer (1984).

\section{Analyzing Culture for Bounded Learning Communities}

1. Briefly describe the learning community being analyzed and the constrants that define its dewelopment:

2. Compare and reflect on the fomol structure of the class with the infomolstructure of power and communication. How are these aligned? How are they mutually compatible or competing with each other?

3. Identify some infomal leaders and how they may contribute to establishing community.

4. Consider any existing or contemplated rituals used within the cousse. If rituals are not presently in place, try to develop some that may be appropriate.

- Rites of possoge hep indiwidals form their identity, identify points of transition, celebrate progress, and bring closure to life changes.

- Rites of degradotion communicate to a person and the group that a person is no longer a member of the community or has perfomed inadequately. [Note: Most forms of this kind of rite may be inappropriate in courses, due to the negative motivational effects of forced social comparisons.]

- Rites of enhonoment recognize a person's standing or accomplishments.

- Rites of renewal help clase members asess the group's progress and identify ways in which the course experience can be improved.

- Rites of confict reduction offer ways to resolve conflict in legitimate and sanctioned ways.

- Rites of integration occur when group nembers assemble to increase their solidarity and shared identification with the organization.

5. Identify any stories that help define the course, its content, or the community.

6. What are some symbols or metophors that help shape the local culture?

7. Who are some of the heroes valued within the course or the group?

8. Note any distinctive language used within the course.

Points 1-3 in the job aid acknowledge the power structures within a class, and the important roles that particular class members play in achieving community. Instructors are well-advised to identify early on informal leaders, including those who may not participate as actively, but whose beliefs and attitudes are influential within the group. Instructors who are able to assess the talent and resources within a group, and then tap that talent for the good of the group - these instructors will be more successful in establishing a strong sense of community.

Point 4 of the job aid asks instructors to reflect on various functions that happen within community - passage, renewal, conflict reduction, and so forth - and look for outward forms and rituals that could relate to those functions. Rituals or symbols relating to these critical functions could help orient the student toward the rhythm, pacing, and expectations of the course. An instructor, for example, may pace the course to rise to a climax of participation and challenge, to 
be followed with a calmer time of reflection and consolidation (see Parrish, 2004, and Parrish, in press, for more on dramatic pacing in courses). A specific ritual such as a poster session could denote closure on one phase and movement toward the next.

The remaining points in the job aid consider stories, symbols, heroes, and language, all of which may be used to strengthen community. Instructors who are cognizant of local culture may specifically design the course with these items in mind, particularly at early stages. One instructor in an on-campus Master's program begins a leadership class by decorating a classroom with a Polynesian theme and having students engage in a number of ritual-type activities. This sends a clear message to students that the course is different from others they have taken, that they need to loosen their schemas, pay attention, and be prepared to exercise their imagination and do things differently. Students in that class are likely to develop a distinctive sense of community based on the unusual rituals and symbols used by the instructor throughout the course.

\section{Strategies for Strengthening Bounded Communities}

Table 2 presents a number of strategies within each of the seven features of learning communities. Instructors experienced in supporting learning communities will doubtless have additional ideas and strategies to add to the list.

Table 2. Sample strategies for leading, supporting, and facilitating effective learning community membership.

\begin{tabular}{|l|l|}
\hline Feature & Facilitating Strategies \\
\hline Shared goals & $\begin{array}{l}\text { Build course around projects and challenges that are authentic } \\
\text { and meaningful to leamers. }\end{array}$ \\
$\begin{array}{l}\text { Ask each learner to share herihis goals for the leaming } \\
\text { experience. As a community, have the learners detemine } \\
\text { commonalities and differences across goals, detemine which } \\
\text { goals can be addressed by the community, prioritize those goals, } \\
\text { create action plans for fulfilling the goals, and offer suggestions } \\
\text { for fulfilling individual goals not embraced by the community. }\end{array}$ \\
$\begin{array}{l}\text { Have learners develop assessment rubrics for community work } \\
\text { based on shared goals. }\end{array}$ \\
\hline
\end{tabular}




\begin{tabular}{|c|c|}
\hline $\begin{array}{l}\text { Safe and } \\
\text { supporting } \\
\text { conditions }\end{array}$ & $\begin{array}{l}\text { Allow private subgroups and private discussions. } \\
\text { Post private profiles and appropriate personal infomation. } \\
\text { Model community participation skills including tum-taking, } \\
\text { netiquette, thoughtful responses to peers' posts, and organization } \\
\text { and facilitation of community events or chat. } \\
\text { Actively monitor the community discussions early on to answer } \\
\text { questions, provide feedback, resolve conflicts, and guide } \\
\text { discussion as needed. } \\
\text { Train students to serve the monitoring role in discussions, then } \\
\text { transfer leadership to them. } \\
\text { Establish a contingency plan to deal with technical challenges. } \\
\text { Have learners fomally set "rules of engagement" for the } \\
\text { community. }\end{array}$ \\
\hline
\end{tabular}

\begin{tabular}{|c|c|}
\hline $\begin{array}{l}\text { Community } \\
\text { identity }\end{array}$ & $\begin{array}{l}\text { Have learners: } \\
\text { - Create a promotional campaign used to encourage others } \\
\text { to join the community. } \\
\text { - Develop a community logo and motto to be used on all } \\
\text { community materials (e.g., website, reports). } \\
\text { - Create personal profiles and a community profile. } \\
\text { - Establish cyclical events that encourage ongoing leamer } \\
\text { participation. } \\
\text { Generate email reminders or updates to be sent to learners based } \\
\text { on their preferences. The emails could notify leamers to new } \\
\text { postings to the community, upcoming events or guest speakers, } \\
\text { deadlines, etc. } \\
\text { continually add fresh content to the environment and embed } \\
\text { scaffolding to guide learners to the resources. }\end{array}$ \\
\hline
\end{tabular}




\begin{tabular}{|l|l|}
\hline Collaboration & $\begin{array}{l}\text { Provide adequate tools for communication and self-presentation. } \\
\text { Allow (or assign) leamers to develop subgroups to focus on tasks } \\
\text { and projects. }\end{array}$ \\
$\begin{array}{l}\text { Provide for different leamer roles within teams and within the } \\
\text { community. }\end{array}$ \\
$\begin{array}{l}\text { Train leamers in specific team roles. } \\
\text { Utilize open-ended topics that encourage members to identify } \\
\text { multiple solution options. } \\
\text { Have learners work as a community on authentic problems of } \\
\text { practice. } \\
\text { Provide (or have learners develop) a rubric for assessing effective } \\
\text { collaborative contributions. } \\
\text { Develop a reward system that targets collaborative work. }\end{array}$
\end{tabular}

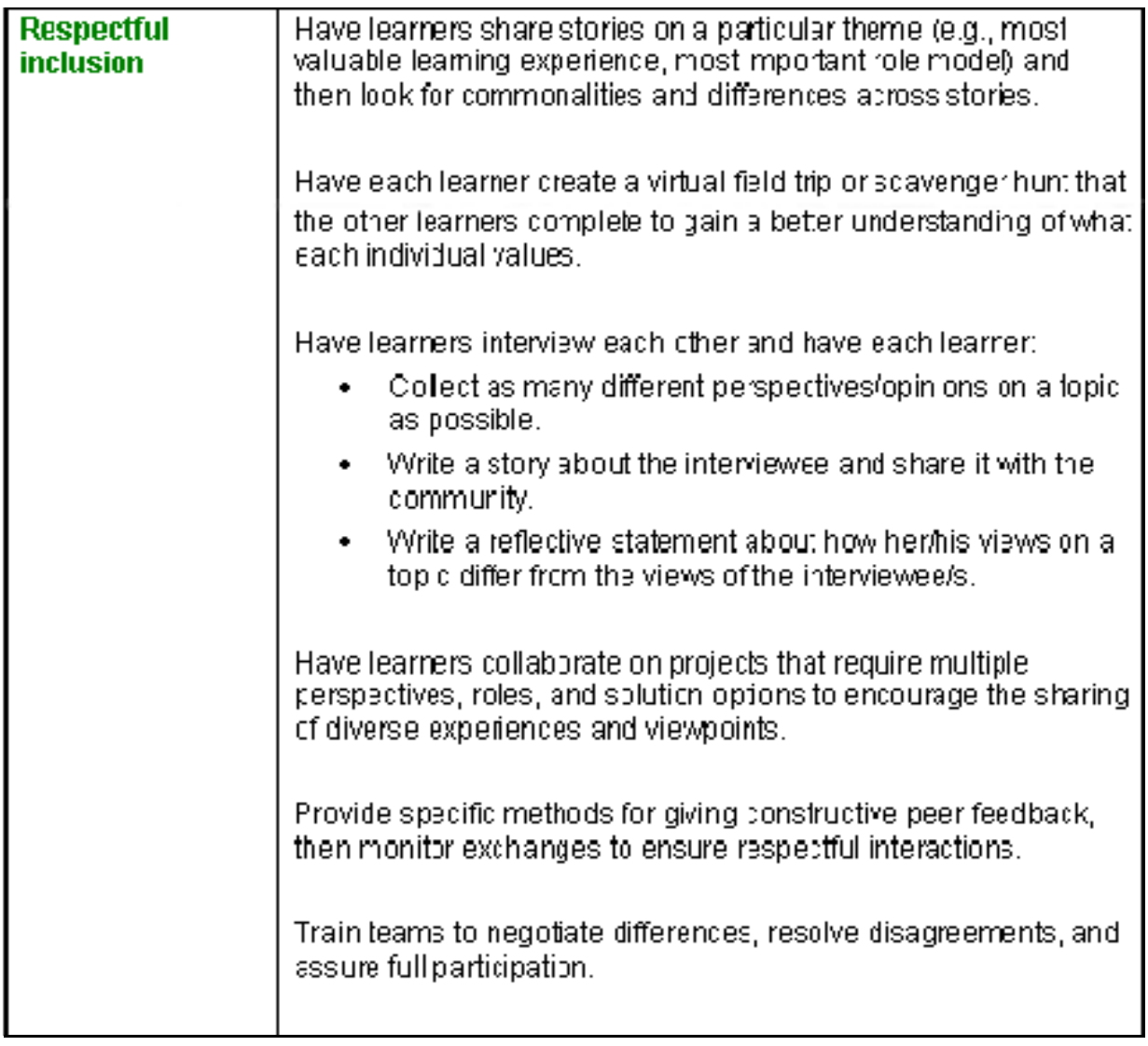




\begin{tabular}{|c|c|}
\hline $\begin{array}{l}\text { Progressive } \\
\text { discourse toward } \\
\text { knowledge } \\
\text { building }\end{array}$ & $\begin{array}{l}\text { Have learners assign "kama points" to community colleagues } \\
\text { bas ed on the value of their contributions. } \\
\text { Each week, have a different learner summarize the previous } \\
\text { week's discourse and bring fomard the key points, action items, } \\
\text { unanswered questions, etc. } \\
\text { Involve learners in a progressive writing or product building } \\
\text { project. Each leamer adds something to the story or product and } \\
\text { passes it on to the next learner. When completed, have leamers } \\
\text { reflect on various passages or aspects and describe the author'si } \\
\text { contributors perspective, assumptions, expertise, background, } \\
\text { etc. } \\
\text { Involve learners in debates and role-plays where learners have to } \\
\text { take positions opposite of their owh. } \\
\text { Invite experts to the community to share ideas and facilitate } \\
\text { discussion. }\end{array}$ \\
\hline $\begin{array}{l}\text { Mutual } \\
\text { appropriation }\end{array}$ & $\begin{array}{l}\text { Assign each learner to be a me ntor to another community } \\
\text { colleague for a particular topic. Every learner has an opportunity } \\
\text { to be a mentor and a mentee. } \\
\text { Engage learners in a jigsaw activity. Each small group develops } \\
\text { expertise in a particular area, and then expertise group members } \\
\text { are dispersed to new groups in which each group member has } \\
\text { unicye expertise. These new groups work on compelling } \\
\text { problems of practice, bringing their expertise to bear on the } \\
\text { problem and teaching the other group members in the process. } \\
\text { Have learners share or rotate leadership roles within groups. }\end{array}$ \\
\hline
\end{tabular}

We encourage consideration of these strategies within the three phases of the development arc discussed above. For instance, the initiation stage may focus on developing safe and supporting conditions and community identity. During the participation stage focus may turn to identifying shared goals, collaboration, and respectful inclusion. With most of these elements in place, learners may be prepared to engage in progressive discourse and mutual appropriation in support of knowledge building. Closure can be a time to re-examine community identity and reflect on the intensive activities of the participation phase. Students can further link knowledge together and consolidate gains, ensuring a better match to performance expectations beyond the course.

\section{Tools for Assessing Community}

Students in a bounded learning community would be expected to report a sense of belonging to that community. A research instrument has been developed to formally measure sense of community (Rovai, Lucking, and Cristol, 2001; see also McMillan, 1996, and Rovai and Lucking, 2003). This instrument is based on a somewhat different conceptual base than our seven features. Moreover, instructors need a shorter, more focused instrument for routine use in classes. Figure 3 offers a draft of a simple instrument for assessing levels of community within courses. 
Figure 3. Draft measure for sense of community, not yet validated, designed for routine use in elearning and face-to-face classes (see Rovai, Lucking, and Cristol, 2001, for a more rigorous measure). Italicized items are reverse scored.

\section{Sense of Community for BLCs}

\section{Shared Goals}

Students in this class are focused on certain goals we have in common.

Projects and activities give us a sense of working together for something worthwhile.

\section{Safe and Supportive Conditions}

People feel comfortable expressing their thoughts and ideas.

i wouldn't take too many risks in this class; not a safe envionment.

\section{Collective Identity}

We enjoy a sense of connection.

There is really a feeling of belonging in this class.

\section{Collaboration}

We interact and work together a lot in this class.

There's not much student-to-student contact in this class.

\section{Respectful Inclusion}

Differences between people are respected.

Not much effort it made to help everyone fit in.

\section{Progressive Discourse toward Knowledge Building}

our questions and discussions help us build knowledge together.

I know why I'm working on projects-to learn better!

\section{Mutual Appropriation}

We teach each other a lot in this class, not just relying on the teacher.

There's room for everyone in this class.

Having access to a measure of community seems critical for instructors, if they are to make iterative improvements in their courses. We are presently working to refine and validate a short measure for this purpose, and will report on that effort in the future.

\section{Conclusion}

If learners have truly identified with a learning community within a course, the closure phase may actually lead to further interactions outside of the course as students stay in touch and continue correspondence. Thus closure on a bounded group may initiate an un bounded community beyond the confines of a course. While this kind of continuing engagement cannot be strictly expected as an outcome, conditions can be encouraged to facilitate lasting relationships.

Course-based learning communities can bring the experience of schooling closer to everyday life by grounding experiences in community participation. Through course activities, students can establish contact with outside communities of practice, beyond the walls of the school (Wenger, 
1998). This transfer to practice may be rare, but it is more likely to occur within active learning communities.

This, indeed, is one of the strengths of a learning-community approach to coursework: The participation skills gained relate very well to the lifelong learning roles expected of adults in society (Dunlap and Grabinger, 2003). Very similar skills are needed for successful participation in communities of practice. Having begun with specific consideration of bounded participation, we are nonetheless reminded that courses are not - or should not be - fully self-contained, closed systems. Rather, course boundaries should be porous - sufficiently defined to establish a clear sense of community within, but flexible enough to accommodate outside resources, including people, information, and field interactions.

The idea of community within courses is partly an issue of what works, and developing appropriate models and strategies to help things work better. Design research and instructionaldesign theories can help us develop strategies that "work" effectively. Community is also a value, however, a commitment toward valuing certain learning over other outcomes. Technical skill acquisition is doubtless of value, but even more valuable is the ability to use a skill to solve an authentic problem. Helping people in the transition to the workplace is a high value, and this transition is aided through work-like collaboration in courses. Teachers are valuable information sources, but even more valuable as they help students construct understanding through activity. In this respect, instructional design converges with curriculum concerns of what should we be teaching, how should we be preparing students for roles outside the classroom. This convergence of technical/ theoretical and value/ political concerns is actually a very positive condition. By directly confronting the value questions surrounding ideas of community, teachers are more likely to see their concerns addressed. With the practical support of strategies and technologies, teachers are then more likely to find success in their efforts.

\section{References}

Backroad Connections Pty Ltd. (2003). What are the conditions for and characteristics of effective online learning communities? (Version 1.00). In the Australian Flexible Learning Framework Quick Guides series, July. Australian National Training Authority. Retrieved March 22, 2004 from: http://www.flexiblelearning.net.au/guides/community.pdf

Barab, S., Barnett, M., and Squire, K. (2000). Preparing Pre-Service Teachers: Developing an empirical account of a community of practice. Retrieved May 3, 2001 from: http://inkido.indiana.edu/research/copfrt.html

Barab, S. A., and Duffy, T. M. (2000). From practice fields to communities of practice. In D. H. Jonassen and T. M. Duffy (Eds.) Theoretical foundations of learning environments (p. 25-55). Mahwah, NJ.: Lawrence Erlbaum. Retrieved May 7, 2001 from: http://it.coe.uga.edu/itforum/paper28/paper28.html

Bereiter, C. (1994). Implications of postmodernism for science, or, science as progressive discourse. Educational Psychologist, 29(1), 3 - 12.

Brown, A. L., and Campione, J. C. (1994). Guided discovery in a community of learners. In K. McGilly (Ed.) Classroom lessons: Integrating cognitive theory and classroom practice (p. 229-270). Cambridge, MA.: Massachusetts Institute of Technology. 
Butt, R. (1999). Towards the Learning Community: Working through barriers between teacher development and evaluation. In J. Retallick, B. Cocklin, and K. Coombe (Eds.) Learning Communities in Education: Issues, strategies and contexts (p. 60-85). London: Routledge.

Calderwood, P. (2000). Learning Community: Finding common ground in difference. New York: Teachers College of Columbia University.

Coombe, K. (1999). Ethics and the learning community. In J. Retallick, B. Cocklin and K. Coombe (Eds.) Learning Communities in Education: Issues, strategies and contexts (p. 86-104). London: Routledge.

Donath, J. S. (1999). Identity and deception in the virtual community. In M. Smith and P. Kollock (Eds.) Communities in cyberspace (p. 29-59). London: Routledge.

Downes, S. (1998). The future of online learning. Retrieved April 29, 2001 from: http://www.atl.ualberta.ca/downes/future

Dunlap, J. C., and Grabinger, R. S. (2003). Preparing Students for Lifelong Learning: A review of instructional methodologies. Performance Improvement Quarterly, 16(2), 6 - 25.

Etzioni, A., and Etzioni, O. (1997). Communities: virtual vs. real. Science, 277(5324), p. 295.

Gardner, D. L. (1991). Presence. In G. Bulechek and J. McCloskey (Eds.). Nursing Interventions: Treatments for nursing diagnoses (p. 191-200). Philadelphia, PA.: W. B. Saunders.

Grabinger, S., and Dunlap, J. (1996). Rich environments for active learning. In P. Kommers, S. Grabinger and J. C. Dunlap (Eds.) Hypermedia Learning Environments: Instructional design and integration. Mahwah, NJ.: Lawrence Erlbaum.

Hand, S. (Ed.). (1989). The Levinas reader. Cambridge, MA.: Blackwell.

Hiltz, S. R. (1998). Collaborative Learning in Asynchronous Learning Networks: Building learning communities. Paper presented at the WEB98 November. Orlando, Florida. Retrieved April 13, 2001 from: http://eies.njit.edu/ hiltz/collaborative learning in asynch.htm

Jonassen, D., Peck, K., and Wilson, B. (1999). Learning with Technology: A constructivist perspective. Upper Saddle River, NJ.: Merrill.

Kollock, P. (1996). Design Principles for Online Communities. Paper presented at the Harvard Conference on the Internet and Society November. Also published in PC Update 15(5): 58 - 60. June 1998.

Lave, J., and Wenger, E. (1991). Situated Learning: Legitimate peripheral participation. Cambridge, UK.: Cambridge University Press.

Lawrence, R. L. (1997). Building a learning community. Paper presented at the Midwest research-to-practice conference in adult, continuing and community education, April. 
Michigan State University. Retrieved May 3, 2001 from:

http://nlu.nl.edu/ace/Resources/Documents/LearnCommunity.html

Levin, J. (1995). Organizing Educational Network Interactions: Steps towards a theory of network- based learning environments. Paper presented at the meeting of the 1995 American Educational Research Association, April. San Francisco, CA.

Lombard, M., and Ditton, T. (1997). At the heart of it all: The concept of presence. Jo'rnal of Computer Mediated Communication, 3(2). Retrieved August 1, 2001 from: http://www.ascusc.org/jcmc/vol2/issue2/lombard.html

Ludwig-Hardman, S. (2003). Case study: Instructional design strategies that contribute to the development of online learning community. Unpublished doctoral dissertation. Denver: University of Colorado.

Ludwig-Hardman, S., and Dunlap, J. C. (2003). Learner Support Services for Online Students: scaffolding for success. The International Review of Research in Open and Distance Learning, 4(1). Retrieved September 17, 2004 from: http://www.irrodl.org/content/v4.1/dunlap.html

McMillan, D. W. (1996). Sense of community. Journal of Community Psychology, 24(4), 315 325.

Palloff, R. N., and Pratt, K. (1999). Building learning communities in cyberspace. San Francisco: Jossey-Bass Inc.

Palmer, P. (1999). Change: Community, conflict, and ways of knowing to deepen our educational agenda. Paper presented at the All-Faculty Convocation, Scottsdale Community College, September. Retrieved April 22, 2001 from:

http://www.mcli.dist.maricopa.edu/events/afc99/articles/change.html

Parrish, P. E. (2004). Investigating the aesthetic decisions of instructional designers. Paper presented at the 2004 meeting of the American Educational Research Association, April. San Diego, CA.

Parrish, P. E. (in press). Why we don't talk about the aesthetics of instruction (and why we should). Educational Technology, special issue on cultural studies, edited by Ellen Rose.

Retallick, J. (1999). Transforming schools into learning communities. In J. Retallick, B. Cocklin, and K. Coombe (Eds.) Learning Communities in Education: Issues, strategies and contexts (p. 107-130). London: Routledge.

Riel, M. (1996). Learning circles. AT\&T website. Retrieved May 5, 2001 from: http://www.att.com/education/lcguide/p.intro/a.intro.html\#Concept

Riel, M., and Fulton, K. (2001). The role of technology in supporting learning communities. Phi Delta Kappan, 3, 518 - 523.

Rogers, E. M. (1995). Diffusion of Innovations (4th ed.). New York: Free Press. 
Rovai, A. P., and Lucking, R. (2003). Sense of community in a higher education television-based distance education program. Educational Technology Research \& Development, 51(2), 5 -16 .

Rovai, A. P., Lucking, R. A., and Cristol, D. (2001). Sense of Classroom Community Index. Unpublished attitude measure.

Scardamalia, M., and Bereiter, C. (1994). Computer support for knowledge-building communities. The Journal of the Learning Sciences, 3(3), 265 - 283.

Scime, R. (1994). <cyberville> and the Spirit of Community: Howard Rheingold-meets Amitai Etzioni. Retrieved April 29, 2001 from: http://www.imagination.org/cyberville/cyberville.html

Senge, P. (2000). Schools that Learn. New York: Doubleday.

Sergiovanni, T. (1999). The story of community. In J. Retallick, B. Cocklin and K.Coombe (Eds.) Learning Communities in Education: Issues, strategies and contexts (p. 9-25). London: Routledge.

Thornam, C. L. (2003). Teaching presence in face-to-face and online learning environments. Unpublished doctoral dissertation. Denver: University of Colorado.

Trice, H. M., and Beyer, J. M. (1984). Studying organizational cultures through rites and ceremonials. Academy of Management Review, 9, 653 - 659.

Vygotsky, L. S. (2003). Mind in Society. In M. Cole, V. John-Steiner, S. Scribner, and E. Souberman (Eds.) Mind in Society: The development of higher psychological processes 5th edition. Cambridge, MA.: Harvard University Press.

Wellman, B., and Gulia, M. (1999). Virtual Communities as Communities: Net surfers don't ride alone. In M. Smith and P. Kollock (Eds.) Communities in Cyberspace (p. 167-194). London: Routledge.

Wells, P. (1999). Different and Equal: Fostering interdependence in a learning community. In J. Retallick, B. Cocklin, and K. Coombe (Eds.) Learning Communities in Education: Issues, strategies and contexts. London: Routledge.

Wenger, E. (1998). Communities of Practice: Learning, meaning, and identity. Cambridge, UK.: Cambridge University Press.

Wenger, E. (1998). Communities of Practice: Learning as a social system. Systems Thinker 9(5). Retrieved April 29, 2001 from: http://www.co-i-l.com/coil/knowledgegarden/cop/lss.shtml

Wilson, B. (2001). Sense of community as a valued outcome for electronic courses, cohorts, and programs. Retrieved December 10, 2001 from: http://carbon.cudenver.edu/ bwilson/SenseOfCommunity.html 
Wilson, B., and Ryder, M. (1996).Dynamic Learning Communities: An alternative to designed instruction. In M. Simonson (Ed.) Proceedings of selected research and development presentations (p. 800-809). Washington, D. C.: Association for Educational Communications and Technology. Retrieved March 20, 2004, from: http://carbon.cudenver.edu/ bwilson/dlc.html

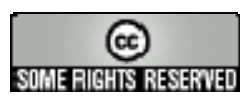

